\title{
Enzimas vegetais: extração e aplicações biotecnológicas
}

\section{Plant enzymes: extraction and biotechnological applications}

Recebido em: 07/11/2016

Aceito em: 28/04/2017

\author{
Rafael Souza ANTUNES ${ }^{1}$; Flavio Marques LOPES ${ }^{1}$; Andressa de Oliveira BRITO²; \\ Luane Ferreira GARCIA ${ }^{1}$; Denes Ferraz de SOUSA ${ }^{2}$; Eric de Souza GIL ${ }^{1}$ \\ ${ }^{1}$ Universidade Federal do Goiás (UFG), Faculdade de Farmácia, Rua 240, esquina com \\ a $5^{a}$ Avenida, $s / n^{\circ}$ Setor Leste Universitário, CEP: 74605-170. Goiânia, Goiás, Brasil. \\ ${ }^{2}$ Universidade Estadual de Goiás - Campus Henrique Santilo. BR-153, 3105 - \\ Fazenda Barreiro do Meio, CEP: 75132-903. Anápolis, Goiás, Brasil. \\ E-mail: flaviomarques.ufg@gmail.com
}

\section{ABSTRACT}

The manuscript describes the current analytical methodologies used in obtaining plant enzymes for biotechnological applications. The isolation and partial purification methods are reported, summarized in chromatographic electrophoretic techniques. The importance of these enzymes in biotechnology research, with a focus on its applications, characteristics and peculiarities, are emphasizing either. With regard to the applicability, the article brings several examples in food production, manufacturing and production of biosensors for determination of various analytes. About bioremediation, we aimed on pollutant removal of the natural environment and its conversion into less harmful products, using those plant enzymes. Industrial interests are also discussed.

Keywords: biotechnology; food production; biosensing techniques; bioremediation.

\section{RESUMO}

O artigo descreve as metodologias analíticas atuais mais utilizadas na obtenção de enzimas vegetais para aplicações biotecnológicas. São relatados os métodos de isolamento e purificação parcial, que se resumem nas técnicas cromatográficas e eletroforéticas, enfatizando a importância dessas enzimas nas pesquisas em Biotecnologia, com foco nas suas aplicações, características e peculiaridades. No que se refere à aplicabilidade, o artigo traz diversos exemplos na produção de alimentos, na fabricação e produção de biossenssores para determinação de diversos analitos e na biorremediação, que que tem como objetivo a remoção de poluentes do ambiente natural e a sua conversão em produtos menos prejudiciais, utilizando, para isso, as enzimas vegetais. Interesses industriais também são discutidos.

Palavras-chave: produção de alimentos; técnicas biossensoriais; biorremediação.

\section{INTRODUÇÃO}

A Biotecnologia é o conjunto de técnicas que permitem gerar produtos de interesse econômico e social a partir de organismos vivos ou de seus componentes (1). Nas últimas décadas apresentou uma expansão de aplicações bem sucedidas em produtos e técnicas, principalmente aquelas envolvendo enzimas (2). As enzimas são consideradas catalisadores biológicos, por exercerem a função de acelerar ou mesmo possibilitar reações entre componentes químicos (3). Estão presentes em todos os sistemas biológicos, são produzidas por todos os organismos vivos e são responsáveis por vários processos metabólicos (4).

As enzimas são o principal alvo da pesquisa em Biotecnologia, não apenas por seu papel crucial nos me- 
canismos celulares, mas também por seu potencial de aplicação na substituição de processos químicos convencionais, fazendo com que estes passem a ser mais utilizados em processos industriais, e até mesmo em atividades domésticas no decorrer dos anos $(5,6,7)$.

Enzimas possuem características particulares pela sua alta eficiência em condições fisiológicas e alta especificidade (biocatalisadores), sendo inclusive capazes de catalisar reações estereoespecíficas, em situações extremas como em meio orgânico, sistemas bifásicos e meio reacional contendo líquidos iônicos. Tais potenciais enzimáticos são amplamente utilizados em diferentes setores produtivos, desde indústrias de beneficiamento e produção de alimentos até produtos farmoquímicos. Uma vez que é necessária a síntese de compostos enantiomericamente puros, a manipulação enzimática melhora a produção de fármacos, produtos agroquímicos, flavorizantes, aromas (fragrâncias) $(8,9)$.

Ainda no que concerne a produção, as enzimas se destacam também na tecnologia petroquímica, em processos industriais que usam a microbiologia na produção de biogás, com acentuada comercialização mundial (10).

As enzimas também podem se constituir em biomarcadores igualmente relevantes no diagnóstico de patologias como na determinação de espécies taxonômicas (11). Por sua vez, dada sua inerente seletividade e eficiência, as enzimas apresentam ainda outras aplicações biotecnológicas, tais como desenvolvimento de ensaios de diagnósticos (12) e biossensores (13).

Neste contexto, novas fontes enzimáticas têm sido investigadas no sentido de oferecer ao mercado biotecnológico produtos com preços acessíveis com boa estabilidade e seletividade (14). Os vegetais Ananas comosus (abacaxi), Avena sativa (aveia) e Carica papaya (mamão), por exemplo, por serem conhecidos como grandes produtores de enzimas, destacam-se neste cenário (15).

O Brasil tem uma grande diversidade de vegetais que podem constituir em fontes sustentáveis de enzimas para serem aplicados nas mais diversas áreas do conhecimento (16). Uma proporção desses vegetais se apresenta como fonte primária de alimentos e também é usada como medicamentos fitoterápicos, portanto é uma alternativa promissora na obtenção de enzimas para inúmeras aplicações biotecnológicas, alinhando conhecimentos populares com evidências científicas (17).

Em razão da grande demanda e utilização destas enzimas vegetais, processadas e purificadas, o presente trabalho tem como objetivo contextualizar e revisar o cenário dos processos de isolamento e purificação de enzimas vegetais de suas diversas fontes, bem como mostrar algumas de suas principais aplicações. São descritos os principais métodos utilizados na obtenção do material vegetal, extração, isolamento e purificação das enzimas e as aplicações biotecnológicas em que elas estão inseridas.

\section{Métodos de Obtenção de Amostras e Enzimas Ve- getais}

Dentre as etapas frequentemente envolvidas em procedimentos sequenciais de purificação, destacam-se: a preparação do material vegetal (fonte enzimática), a purificação parcial e o isolamento enzimático e a sua caracterização (18).

Obtenção de tecido vegetal. As amostras obtidas de vegetais são muito variáveis quanto aos aspectos físicos tais como friabilidade, maleabilidade e dureza. Com isso, o preparo do material vegetal antes das análises se torna de fundamental importância. Folhas, frutos, tubérculos e raizes geralmente são faceis de serem rompidos usando um moinho, por exemplo. Por outro lado, cascas, caules e sementes possuem paredes celulares rigidas e requerem equipamentos mais específicos (19).

Seja qual for o tecido escolhido como fonte enzimática, deve ser levado em conta também as variações sazonais, genéticas e o estágio de vida das plantas na determinaçao do teor dos produdos almejados pois eles sofrem interferência direta em seus níveis $(20,21)$.

Em todos os casos, o material vegetal deve ser preferencialmente micromizado ou reduzido a pó, a fim de elevar a área de contato com líquidos extratores. $\mathrm{O}$ uso de solventes apolares como éter ou acetona tem sido preconizado para remoção de compostos hidrofóbicos, tais como látex, lípidios e terpenos. Posterior a este processo comumente referido como desengorduração, dá-se a extração em solventes mais polares, que frequentemente incluem o uso de uma solução tampão adequada $(22,23)$.

Os derivados de vegetais variam muito quanto a seus componentes químicos e respectivos teores. Assim, dependendo de suas características intrínsecas, estes componentes podem causar modificação estrutural de proteínas no momento do isolamento. Como exemplo, a presença de derivados fenólicos e proteases pode formar complexos inativando ou inibindo algumas enzimas (24). 
Conservação da amostra vegetal. Levando em consideração que muitas vezes é necessário dissecar o tecido vegetal e homogeneizá-lo, é obtida, assim, uma solução chamada extrato vegetal bruto. Para que isso ocorra, alguns métodos físicos, químicos e até mesmo enzimáticos são utilizados nesse procedimento para se obter a enzima vegetal por meio da extração aquosa convencional $(25,7)$. Por exemplo, no intuito de manter a atividade enzimática, algumas estratégias têm surgido no sentido de processar o fruto fresco previamente congelado (submetidos ou não ao estresse salino) e obtenção do pó (26), ou pasta gelada / sorvete (27).

Obtenção de enzimas vegetais. Outra questão diz respeito à conservação (manutenção) da estrutura terciária na forma ativa da enzima, pois muitos processos de purificação e isolamento podem levar à desnaturação desses polipeptídios, frequentemente de forma irreversível. Logo, as técnicas devem primar por condições mais brandas, evitando sempre a possível utilização de $\mathrm{pH}$ extremos, solventes orgânicos, detergentes, meios hidrofóbicos ou mesmo de colunas cromatográficas cuja afinidade possa comprometer a integridade da enzima $(28,29)$.

Em um processo de purificação deve ser levado em conta a aplicação na qual a proteína será utilizada e, consequentemente, a quantidade de enzima necessária, que pode variar de poucos miligramas a quilogramas (30). É importante ressaltar que esse processo estará sujeito a limitações operacionais, relacionadas ao custo, facilidade de obtenção da enzima e fatores físicos, tais como a capacidade de suporte do sistema de separação (31).

Um dos grandes desafios dos processos de purificação das proteínas, principalmente quando se trata de enzimas vegetais, é o exaustivo trabalho para se encontrar a melhor combinação de métodos para a obtenção da purificação pretendida, chegando às características necessárias para o uso de tal proteína (18).

\section{Métodos de Isolamento e Purificação Parcial de En- zimas Vegetais}

Uma gama de biomoléculas proteicas, de origem vegetal, tem sido utilizada graças ao rápido processo ocorrido na engenharia genética, o que permitiu o desenvolvimento de proteínas recombinantes, expressas em diversas plantas (23). As células vegetais têm sido utilizadas como uma alternativa vantajosa como plataformas de processamento de proteínas na produção de produtos farmacêuticos, agentes de diagnóstico mole- cular e enzimas (11). Os desafios da produção vegetal estão relacionados às diferenças de cultivos, o alto custo de produção, principalmente relacionando ao processamento pós-produção, que interferem diretamente na produção enzimática. Em contrapartida, a obtenção da enzima vegetal necessita de técnicas e procedimentos adequados. Tais técnicas são eficientes em escalas laboratoriais (pequena escala), mas de custo elevado em escala industrial (larga escala), como exemplificado pela cromatografia de afinidade. As etapas de separação e purificação compreendem uma peça chave na produção de tais componentes (2).

Os métodos de purificação deixam o produto desejado com maior grau de pureza, entretanto a estratégia de separação e purificação de uma proteína é empírica, ou seja, baseada em tentativa-erro, e deve ser desenhada para cada proteína individualmente (8).

Existe uma grande variedade de métodos visando a separação e o isolamento de biomoléculas. Muitas vezes, a biomolécula que se pretende purificar é uma proteína que pertence a um grupo de maior diversidade, e será necessário um maior número de metodologias para alcançar os objetivos de purificação. Os métodos mais clássicos utilizados nesses processos são: a precipitação, a centrifugação, a clarificação, a diálise, seguidos dos métodos específicos de cromatografia $(23,31,2)$, que são, em geral, usados sequencialmente, de modo que o material obtido numa fase anterior é o ponto de partida para o passo seguinte. O processamento pós-produção de proteínas tem levado a melhorar as diversas técnicas e procedimentos de obtenção das biomoléculas, uma vez que as características específicas de cada biomolécula podem necessitar de uma combinação específica de métodos para obter um grau de pureza satisfatório com o maior grau de recuperação possível (30).

Precipitação. A precipitação é uma das operações mais tradicionais utilizadas para purificar produtos de origem vegetal, uma vez que obtido o extrato enzimático bruto, a precipitação é utilizada na separação de materiais proteicos e não-proteicos. Esta etapa apresenta como principal vantagem o baixo custo, podendo ser aplicada em pequena e grande escala $(32,33)$.

Neste procedimento há a formação de precipitados proteicos que são agregados compostos por diferentes moléculas proteicas capazes de se sedimentarem. A técnica de precipitação pode ser dividida em dois grupos: a solubilidade da proteína é diminuída devido alterações no solvente e quando há diminuição na solubilidade devido alterações na própria proteína (34). 
A precipitação de proteínas nem sempre proporciona elevada capacidade de purificação quando esta operação se realiza em apenas uma única etapa, portanto no processo de precipitação, há a etapa conhecida como precipitação seletiva, quando há necessidade de separar uma determinada proteína de uma solução que contém várias outras proteínas. Neste processo, a eficiência da precipitação é avaliada principalmente por um fator de purificação e separação. A escolha do agente precipitante para a separação de uma determinada proteína é considerada fundamental no procedimento de purificação (35). Entre os precipitantes, estão ácidos, bases, sais neutros, solventes orgânicos, polieletrólitos, polímeros não iônicos e íons metálicos multivalentes (33).

Centrifugação. $O$ processo de centrifugação é simples e frequentemente utilizado na separação de biomoléculas. A separação é rápida e eficiente, sendo uma das primeiras etapas utilizadas no procedimento de purificação de proteína a partir de extratos brutos (36) (Figura 1).

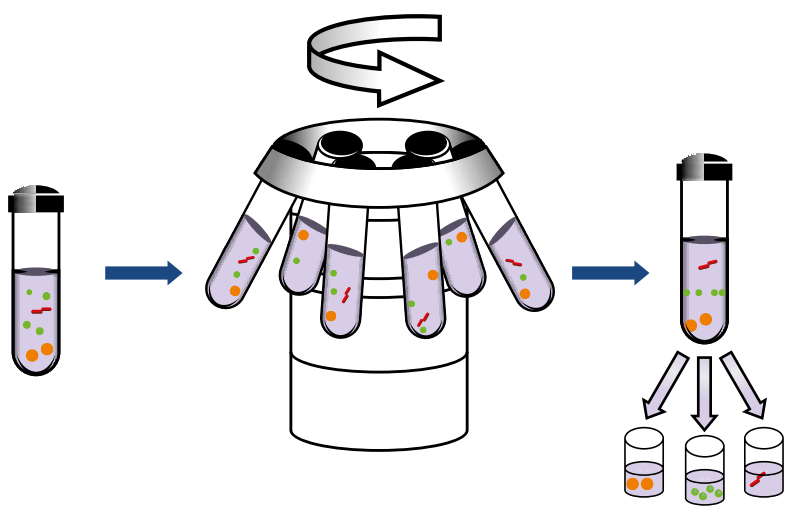

Figura 1. Processo de centrifugação. Separação de pequenas e grandes partículas que ocorrem pela aplicação de diferentes forças centrifugas ao extrato.

A centrifugação é uma técnica que torna possível a obtenção de frações subcelulares, bem como organelas. Nesta técnica, a separação de pequenas e grandes partículas ocorre pela aplicação de diferentes forças centrifugas ao extrato. As partículas maiores e mais densas sedimentam primeiro, ficando no sobrenadante as partículas pequenas e menos densas (13) (Figura 1).

Clarificação. A clarificação é um procedimento físico-químico utilizado para reduzir impurezas em suspensão e turvidez de uma determinada solução, no qual produtos químicos (floculantes e coagulantes) são adicionados para se obter uma amostra límpida (34).

Os processos para obtenção de enzimas em extrato vegetal levam inicialmente à ruptura de tecidos vegetais, liberando impurezas, compostos constituintes da estrutura celular da planta, tais como DNA, RNA, alcaloides, polissacarídeos, clorofila e proteínas solúveis (37). A presença de polifenois em plantas também é considerada inconveniente, uma vez que esses compostos podem promover mudanças conformacionais e estruturais na proteína, originando assim agregados proteínas-polifenois. A remoção preliminar dos compostos polifenólicos dos extratos é de suma importância no processo de purificação $(38,39)$. A filtração e a centrifugação são estratégias recomendadas para promover a clarificação do extrato (40), no entanto podem ser responsáveis por até $25 \%$ dos custos da etapa pós processamento (41) (Figura 2).

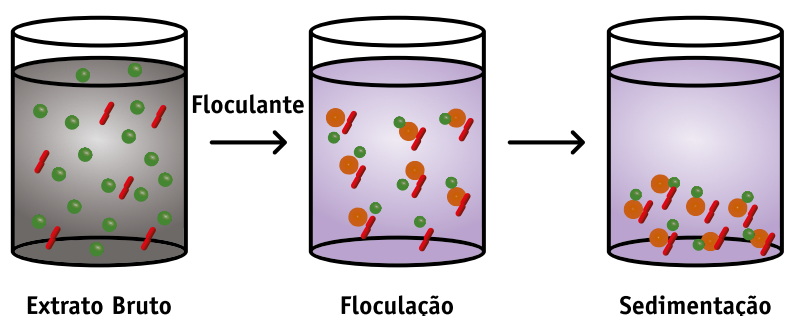

Figura 2. Representação esquemática do processo de clarificação. Redução de impurezas em suspensão na utilização de produtos químicos (floculantes) e sedimentação espontânea.

Separação por membrana (diálise). A separação por membrana é um método utilizado para separar os componentes de uma mistura, por meio do seu tamanho, utilizando membranas semipermeáveis com tamanho do poro definido, de maneira a permitir a passagem seletiva de moléculas de interesse (42). O procedimento baseia-se nos diferentes índices de difusão dos componentes da mistura (43). A separação por membrana tem se tornado um método bastante usual, para remoção de resíduos (i.e. endotoxinas, ácidos nucleicos, proteínas de baixa massa molecular), especialmente em processos de produção que oferece fácil escalabilidade (mudança de escala), condições não desnaturante, e custos mais baixos. O princípio da separação por membranas com poros de tamanho pré-definidos e possibilidade de aplicação de baixas pressões permitiu o desenvolvimento de módulos de filtração seletiva e uma melhor compreensão dos fatores que envolvem e/ou afetam a retenção das partículas (44) (Figura 3).

Cromatografia. A cromatografia é um método físico-químico de separação, que pode ser aplicado à separação de proteínas dissolvidas em uma solução. Trata-se de uma técnica amplamente utilizada devido suas condições brandas de separação e alta resolução (45). 
Alguns tipos de cromatografias são mais utilizadas para esta afinidade, tais como: cromatografia de exclusão molecular (SEC - filtração em Gel), cromatografia de troca iônica (IEC) (cromatografia de troca aniônica (AEC) e/ ou cromatografia de troca catiônica (CEC), cromatografia de interação hidrofóbica (HIC), cromatografia de afinidade (AFC), cromatografia de modo misto (MMC) (46). Todas essas técnicas cromatográficas estão disponíveis comercialmente; desta forma, a escolha ideal do método e o preço tornam-se importantes como critérios de seleção (47).
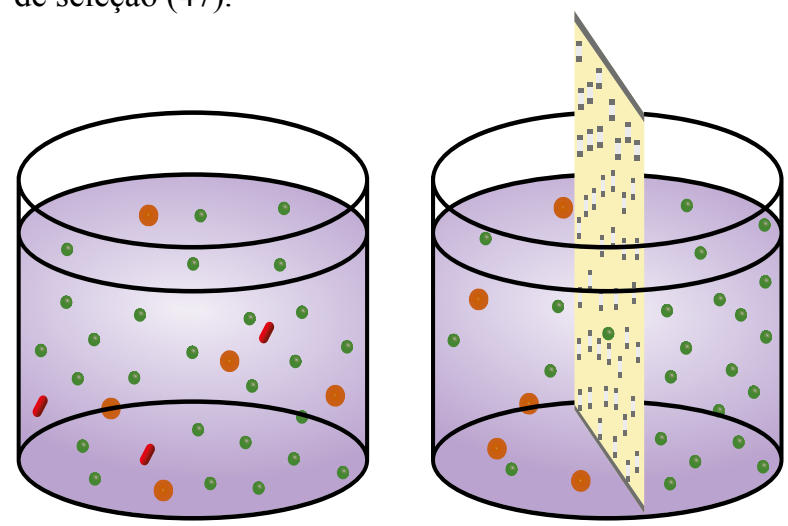

Figura 3. Diálise. Utilização de membranas semipermeáveis com tamanho do poro definido que permitir a passagem seletiva de moléculas de interesse.

\section{Cromatografia de exclusão molecular ou filtra-} ção em gel. A cromatografia de exclusão molecular ou filtração em gel separa proteínas pelos seus diferentes volumes moleculares.


Figura 4. Cromatografia de exclusão molecular. Separação de proteínas por diferentes volumes moleculares. Adaptado de Moraes e cols. (2013)

A matriz é constituída por esferas com poros de tamanho bem definido. As moléculas menores do que o diâmetro dos poros penetram nas esferas, ao passo que as maiores são forçadas a percorrer um caminho diferente, por fora das esferas (48). Deste modo, as moléculas menores percorrem, ao longo de uma coluna, um trajeto muito maior do que as moléculas maiores, que sairão da coluna em primeiro lugar (49) (Figura 4).

As vantagens desse método de separação constituem a não utilização de energia, forças cisalhantes desprezíveis, sistemas simples de automação, alta recuperação aliada à máxima resolução. Consequentemente as desvantagens resumem-se aos problemas de diluição no processo de eluição da coluna (50).

Cromatografia de troca iônica. A cromatografia de troca iônica baseia-se na interação entre cargas (positivas ou negativas) da proteína que está sendo isolada, com uma matriz contendo moléculas ionizáveis de carga oposta (trocadores iônicos, cujos sítios de interação estão carregados positiva ou negativamente), que compõem a coluna (51).

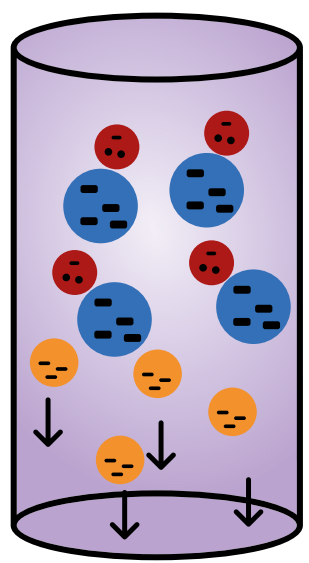

Figura 5. Cromatografia de troca iônica. Separa por interação entre cargas.

Essa cromatografia é uma variante da cromatografia líquida que utiliza resinas de troca iónica para separar íons atômicos ou moleculares com base na sua interação com a resina. A separação dos analitos é conseguida de forma isocrática ou por aplicação de gradiente (52).

É também utilizada para a análise de íons inorgânicos em várias matrizes como águas residuais ou caldos de fermentação (ânions tais como cloreto, fluoreto, nitrito, nitrato e sulfato; cátions como lítio, cálcio, amônia, magnésio, potássio e sódio) (53). Permite analisar ácidos orgânicos alifáticos e ácidos sulfônicos orgânicos, espécies bioquímicas como carboidratos - mono, dissacarídeos e alguns oligossacarídeos; álcoois derivados de carbo-hidratos, aminoácidos, proteínas e outros compostos. Além das aplicações enunciadas é possível desenvolver métodos específicos para outros analitos desde que estejam dentro da gama de operação do equipamento (54) (Figura 5). 
A vantagem desta técnica é que permite a determinação de espécies orgânicas e inorgânicas, com sensibilidade em baixas concentrações ( $\mathrm{mg} / \mathrm{L}$, ou menos), rápido tempo de análise (média de $15 \mathrm{~min}$ ) e pequenos volumes de amostra (1 mL) (52). A desvantagem consiste em equipamentos e reagentes (eluentes e regenerantes) caros e mão-de-obra especializada.

Cromatografia de interação hidrofóbica. Esse método cromatográfico possui como vantagem a utilização do nível de hidrofobicidade da molécula para a separação da mesma por meio da interação hidrofóbica entre a região hidrofóbica imóvel do ligante e a região apolar da superfície da proteína. Em contrapartida, o alto custo do equipamento e a necessidade de operadores experientes se caracterizam como as principais desvantagens deste método (45).

$\mathrm{Na}$ cromatografia por interação hidrofóbica a mistura de proteínas é aplicada a coluna na presença de altas concentrações de sulfato de amônio (sal comumente utilizado). Este sal remove a camada de solvatação das proteínas, expondo as suas regiões hidrofóbicas, que irão interagir com as regiões hidrofóbicas da matriz da coluna. Ao reduzir a concentração de sal na coluna, reconstituindo a camada de solvatação, as proteínas com menor hidrofobicidade serão eluidas primeiro e em seguida as proteínas com maior hidrofobicidade (50).

Cromatografia em fase reversa. A cromatografia emfase reversa utiliza a hidrofobicidade das proteínas para separá-las (48). Esta técnica baseia-se na utilização de uma fase estacionária apolar contendo cadeias longas de hidrocarbonetos e uma fase móvel polar. As proteínas irão se ligar as cadeias de carbono presentes na matriz de acordo com seu grau de hidrofobicidade. As proteínas adsorvidas na matriz serão eluidas em gradiente crescente de solvente apolar (ex., acetonitrila), sendo as proteínas com menor hidrofobicidade eluídas primeiro (55).

Levando em consideração as vantagens e aplicabilidade do método, a cromatografia em fase reversa em comparação com a interação hidrofóbica, apresenta uma matriz cromatográfica com alta hidrofobicidade (56). Com isso, a utilização de solventes orgânicos pode levar à desnaturação da proteína de interesse durante a cromatografia, sendo considerada a grande desvantagem da metodologia, por isso, este tipo de cromatografia não se aplica a um grande número de casos (57).

Cromatografia por afinidade. A cromatografia por afinidade é considerada um dos métodos mais eficientes para a purificação de proteínas, possibilitando um alto rendimento com número reduzido de etapas (58).
A separação de moléculas tem como base a interação específica do analito (molécula-alvo) com um ligante imobilizado na matriz (59).

Esta técnica consiste em imobilizar na matriz cromatográfica, na grande maioria das vezes, através de ligação covalente, de determinada molécula (ligante) pela qual a proteína que se almeja purificar tenha afinidade (58). Posteriormente, o extrato proteico é aplicado à coluna. Todas as proteínas com afinidade para o ligante ficarão retidas na coluna e as outras proteínas passarão através da coluna sem qualquer tipo de interação (56).

As proteínas adsorvidas à coluna poderão ser eluídas com concentrações crescentes de sal ou em valores extremos de pH. Em alguns casos a eluição é feita com uma solução concentrada do próprio ligante (eluição por deslocamento de equilíbrio) (60) (Figura 6).

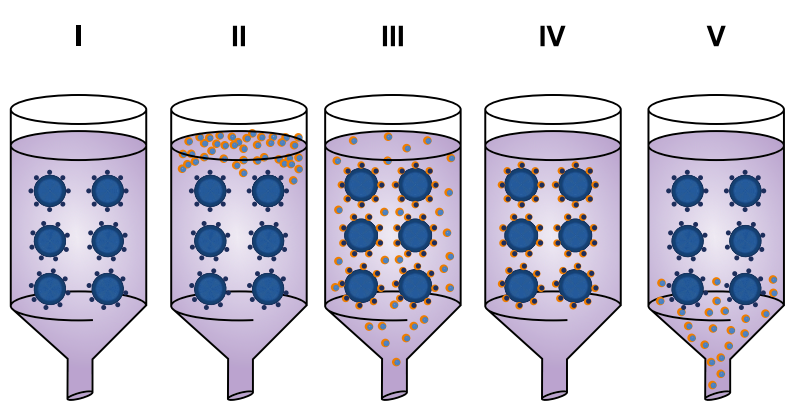

Figura 6. Cromatografia de afinidade. (I) Matriz cromatográfica com ligantes covalentemente presos a fase estacionária. (II) Proteínas com diferentes afinidades estão presentes na amostra aplicada. (III) Proteínas capazes de reconhecer o ligante da matriz interagem com a fase estacionária o restante são eluidas no lavados. (IV) Proteínas ligadas à coluna com alta afinidade permanecem aderidas à matriz mesmo após a lavagem. (V) Após alguma alteração na fase móvel ( $\mathrm{pH}$, concentração de sais, presença de solventes orgânicos ou do próprio ligante na forma solúvel), as proteínas de interesse são eluidas da coluna. Adaptado de Moraes e cols. (2013)

Como vantagens deste método podem ser destacados alta resolução, análise qualitativa, resultados quantitativos e alto nível de detectabilidade. Como desvantagem há o alto custo do equipamento e manutenções, bem como a necessidade de operadores experientes e bem treinados (50).

$\mathrm{Na}$ literatura são encontrados inúmeros trabalhos que envolvem diferentes tipos de métodos de purificação e isolamento de enzimas vegetais. No Quadro 1 são relatados os principais métodos cromatográficos aplicados ao isolamento dessas enzimas. 
Quadro 1. Principais métodos cromatográficos aplicados no isolamento das enzimas vegetais.

\begin{tabular}{|c|c|c|c|c|}
\hline ENZIMAS & MÉTODOS* & COLUNA & FONTE VEGETAL & REFERÊNCIAS \\
\hline \multirow{2}{*}{ Peroxidase } & CTI:CE & - & Ipomea palmata (L.) Sweet & (61) \\
\hline & CE & CM-Sephadex e Sephacryl S-200 & Eruca vesicaria (L.) Cav. & (62) \\
\hline 0xidase & CE & - & Cassia auriculata (L.) Leaves & $(63,59)$ \\
\hline Amino-oxidase & CE & - & Vigna vexillata (L.) Rich. & (64) \\
\hline \multirow{2}{*}{ Peptidase } & CTI & - & Jacaratia corumbensis (L.) Kuntze & (19) \\
\hline & CTI & Dietilaminoetilcelulose (DEAE) & Ananas comosus (L.) Merril & $(52)$ \\
\hline Liase & CE:CTI & Vesipor e DEAE-Celulose & $\begin{array}{l}\text { Triticum vulgare (L.) Pitiní, } \\
\text { Avena sativa (L.) Hausskn; } \\
\text { Cucumis sativus (L.) Kirkbr }\end{array}$ & $(65)$ \\
\hline Isomerase & CA:CE & - & Digitalis lanata (L.) Ehrh & $(66)$ \\
\hline $\begin{array}{l}\text { Didrofolato } \\
\text { Redutase }\end{array}$ & CB:CE & $\begin{array}{l}\text { Metotrexato-amino-hexil-sepharose } \\
\text { Ultrogel AcA-54 e Blue - Sepharose }\end{array}$ & Glycine $\max ($ L.) Merrill & $(67)$ \\
\hline Uricase & CB & Xantina-agarose & $\begin{array}{l}\text { Vicia fava major (L.) Bertol; } \\
\text { Tricum aestivum (L.) Pitiní; } \\
\text { Cicer arietinum (L.) Bornm }\end{array}$ & $(68)$ \\
\hline Amilase & CTI:CE & $\begin{array}{l}\text { DEAE-Sepharose } \\
\text { Sphacryl S-200 }\end{array}$ & Salvadora pérsica (L.) Garcin & $(69)$ \\
\hline Fosfato sintase & CTI:CE & DEAR-Celulose & Lunularia cruciata (L.) Dumort & (70) \\
\hline Transferase & CTI:CA:CB & $\begin{array}{l}\text { SP-Sepharose } \\
\text { Fractogel TSK Butil - } 650 \\
\text { Tripsina imobilizada }\end{array}$ & Carica papaya (L.) Gaertn & (71) \\
\hline
\end{tabular}

Eletroforese. Esta técnica de separação tem como objetivo separar moléculas orgânicas, como as proteínas, de acordo com sua carga elétrica e volume molecular (72). Esta migração segue a Lei de Coulomb, em que partículas de carga positiva migram para o polo negativo (catodo) e partículas de carga negativa migram para o polo positivo (anodo). A velocidade de migração das moléculas é proporcional ao campo elétrico e inversamente proporcional ao seu volume molecular (73). Assim, uma amostra submetida à eletroforese terá cada molécula constituinte localizada em uma zona do gel, onde moléculas com menor volume molecular irão migrar mais rapidamente e as que possuem maior volume molecular irão migrar mais lentamente (74).

Todo o processo de eletroforese é realizado empregando uma solução tampão apropriada, a qual é essencial para manter um estado constante de ionização das moléculas a serem separadas (73). Qualquer variação no pH pode alterar a carga e então a mobilidade (taxa de migração no campo elétrico aplicado) das moléculas que estão sendo separadas.

\section{Eletroforese em gel de poliacrilamida (PAGE).} Essa forma de eletroforese é o método mais utilizado para análise de misturas de proteínas de forma qualitativa (75). Este método é baseado na separação de proteínas de acordo com a carga e o volume molecular. O su- porte amplamente utilizado nessa técnica para proteínas é a poliacrilamida, formada por uma malha transparente estável, gerada pela copolimerização química de monômeros de acrilamida com N,N'-metilenobisacrilamida (Bis-acrilamida) na presença de persulfato de amônio e tetrametiletilenodiamina (TEMED). O TEMED catalisa a liberação de radicais livres do persulfato que, por sua vez, iniciam e aceleram a polimerização (76) (Figura 7).



Figura 7. Suporte (malha) de poliacrilamida. Amplamente utilizado para separação de proteínas.

Eletroforese em condições desnaturantes (SDS-


lizada na bioquímica e biologia molecular para deter- 
minação das massas moleculares relativas das proteínas presentes em uma amostra (72). Este tipo de eletroforese pode ainda ocorrer em condições redutoras, por meio da adição de agentes redutores como ditiotreitol ou beta-mercaptoetanol. Esses agentes complementam a desnaturação das proteínas através da redução de ligações dissulfeto finalizando o processo de desmantelamento das estruturas terciarias e quaternárias (eventuais) previamente a separação eletroforética (77).



Figura 9. Detergente aniônico dodecil sulfato de sódio (SDS), agente desnaturante

O detergente aniônico dodecilsulfato de sódio (SDS) forma interações hidrofóbicas com as proteínas na proporção de uma molécula de detergente para cada dois resíduos de aminoácidos das mesmas. O SDS, então adiciona carga negativa em grande quantidade às proteínas, conferindo-lhes uma carga negativa homogênea. Além disso, o SDS é um agente desnaturante capaz de desfazer parcialmente a estrutura tridimensional de proteínas (78). Entretanto, o detergente não é capaz de romper ligações covalentes como as pontes de dissulfeto (Figura 8).

Eletroforese capilar. Neste tipo de eletroforese é empregado um tubo capilar preenchido com uma solução de eletrólito, assemelhando-se à técnica original descrita por Tiselius, sendo empregada na determinação de amostras como proteínas, peptídeos, hidrocarbonetos, vitaminas, dentre outras (79).

$\mathrm{O}$ equipamento de eletroforese capilar envolve aplicação de alta voltagem em um capilar de diâmetro reduzido gerando correntes de 10 a $100 \mathrm{~mA}$ e um intenso campo elétrico (permitido pela alta resistência elétrica do capilar), que por sua vez favorece a diminuição do tempo de análise, sua eficiência e sua capacidade resolutiva. Também são utilizados, neste tipo de eletroforese, capilares cheios de gel com a aplicação de campos elétricos elevados $(80,79)$.

\section{Aplicações Biotecnológicas em Enzimas Vegetais}

A prospecção de agentes produtores de enzimas é um dos campos mais promissores dentro da Biotecno- logia, não somente pelo fato de agregar grande valor à produção em níveis industriais de materiais de consumo humano, como também por representar a possibilidade de uso mais eficiente dos recursos naturais renováveis de todo o planeta (83). Com o avanço das descobertas, para o conhecimento de substâncias bioativas descritas a partir da década de 50, o uso de enzimas vegetais deu um salto gigantesco, saindo do uso doméstico em pequena escala para o uso em escala industrial de produção (84).

As indústrias têxteis, de papel e celulose, agroquímica, farmacêutica, processamento de couro, biocombustíveis e alimentícia são responsáveis pelo crescimento exponencial do mercado de enzimas vegetais, entre outras. De maneira geral, as enzimas extraídas de vegetais são utilizadas para promover reações de compostos presentes em uma mistura, tendo como objetivo adquirir o produto final dessa reação, como em processos que envolvem coalho (como na fabricação de derivados de laticínios) ou processos fermentativos (como na fabricação de bebidas alcoólicas), eliminar o reagente nocivo inicial gerando um produto inócuo (como na degradação de poluentes e contaminantes de leitos d'água e resíduos industriais), ou, por fim, na identificação e quantificação de substâncias, quando participam de uma reação que possui um efeito físico-químico único e detectável por métodos analíticos (como em ensaios imunológicos rápidos e métodos eletroanalíticos) (17).

Produção de alimentos. As enzimas têm destacado um papel importante no setor alimentício, pois podem influir na composição, no processamento e na deterioração dos alimentos. Elas às vezes são indesejáveis e provocam, por exemplo, o escurecimento de frutas e vegetais (é o caso das polifenoloxidases), o ranço de farinhas (lipases e lipoxigenases) e o amolecimento de tecidos vegetais (enzimas pécticas) (86). Em certas situações, porém, a detecção da atividade prejudicial de uma enzima em um produto pode servir como indicador da eficiência de uma operação (87).

Por outro lado, existem vários exemplos do uso de enzimas vegetais com o objetivo de modificar matérias-primas e obter produtos específicos (84). $\mathrm{Na}$ indústria de laticínios, a quimosina promove a coagulação do leite (para a produção de queijos) e várias plantas fornecem essa peptidase que desestabiliza a caseína do leite, promovendo a coagulação, exemplo: Euphorbia tirucalli (L.) Klotzsch, Euphorbia nerifolia (L.) Chev., Euphorbia nivuliae (L.) Buch, Pedilanthus tithymaloides (L.) Steinm e Jacaratia corumbensis (L.) Kuntze (19, 88, 11). Também, as proteases são utilizadas em razão de 
seu efeito proteolítico e fibrinolítico, que alteram as propriedades de alimentos e outros produtos com alto teor proteico (como em amaciantes de carne). O mamão e o abacaxi, respectivamente Carica papaya (L.) Gaertn e Ananas comosus (L.) Merril, são espécies muito comuns no Brasil e são utilizadas como fonte dessas enzimas (24).

Na panificação, a enzima alfa-amilase promove a decomposição do amido, que leva à produção de maltose, aumentando a maciez e a textura da massa e do miolo e mantendo o pão fresco por mais tempo. A amilase maltogênica e a xilanase dão estabilidade à massa, enquanto a protease altera a elasticidade e a textura do glúten e melhora a cor e o sabor do pão (89). No processamento de amidos, enzimas como glicose isomerase, alfa-amilase, beta-amilase, pululanase e isoamilase convertem o amido em dextrose ou xaropes ricos em açúcares simples. Algumas dessas enzimas também podem ser encontradas em plantas, como ocorre com a alfa-amilase, a qual pode ser extraída da Salvadora pérsica (L.) Garcin, popularmente conhecida como escova de dente natural (69).

A beta-amilase é uma exoenzima que remove unidades de maltose sucessivas de não redução das cadeias de glicídios. A ação é interrompida no ponto onde o acoplamento alfa-1,6-glicosídeo não pode ser quebrado pela alfa-amilase. As combinações resultantes são nomeadas dextrina limite. Malte de cevada, trigo, batata-doce e feijão de soja são boas fontes de beta-amilase (89).

Em sementes, as lipases podem hidrolisar gordura, a menos que as enzimas sejam destruídas pelo calor. O óleo de palma produzido por métodos primitivos na África consistia em mais do que $10 \%$ de ácidos graxos livres. Também são encontrados tais problemas de desperdício em grãos e na farinha. A atividade da lipase em trigo e outros grãos é altamente dependente do conteúdo de água. Na aveia, por exemplo, os elevados índices de lipídeos são almejados quando se destina à alimentação animal, mas pelo elevado teor calórico, é fracionada consideravelmente quando se destina à alimentação humana. Assim o potencial de rancificação, desencadeada pela ação das lipases no processo de descasque ou moagem dos grãos na ausência de água, é diminuído. A atividade lipolítica de aveias é mais alta do que a maioria dos outros grãos (90).

A estabilidade e instabilidade das enzimas vegetais se mostram como um fator determinante para o seu funcionamento. As enzimas possuem uma vida finita de trabalho, devido à instabilidade física inerente, a ação de antagonistas/inibidores e a intoxicação por contaminantes na mistura de reação. Em tecnologia de alimentos, a instabilidade física pode ser induzida pelo efeito de $\mathrm{pH}$ e temperatura, mas também por forças relativamente leves, como a tensão superficial em espumas e emulsões (91).

A maioria dos inibidores de enzima não está presente nos alimentos, porque geralmente são agentes tóxicos (metais pesados e compostos organometálicos, por exemplo); porém, muitos antagonistas da enzima e venenos catalíticos são comuns nos gêneros alimentícios e matérias-primas (i.e., respectivamente, enzimas proteolíticas e radicais livres de ácidos graxos insaturados oxidados) (92).

A estabilidade absoluta de uma enzima só pode ser determinada em sistemas alimentícios reais. Qualquer medição de estabilidade via proteínas purificadas em sistemas tampões aquosos somente fornece uma orientação de como poderá se comportar a enzima na prática, ou primeira decisão a ser tomada é se o processo irá beneficiar de enzimas estáveis ou instáveis (93).

O Quadro 2 mostra exemplos de fatores especiais que influenciam a estabilidade das enzimas nos alimentos e o Quadro 3 traz alguns exemplos de enzimas utilizadas na biotecnologia de alimentos.

Quadro 2. Fatores que influenciam a estabilidade das enzimas nos alimentos.

\begin{tabular}{|c|c|c|c|}
\hline CONDIÇÕES & ESTABILIDADE & CAUSAS SUBJACENTES & REFÊRENCIAS \\
\hline Fase de concentração da enzima & Estabiliza & $\begin{array}{l}\text { Aumenta a energia necessária por unidade de volume para } \\
\text { desnaturar a enzima. }\end{array}$ & $(94)$ \\
\hline $\begin{array}{l}\text { Presença de outras proteínas } \\
\text { não enzimáticas }\end{array}$ & Estabiliza & $\begin{array}{l}\text { Diminui a proporção de energia desnaturante ou fonte } \\
\text { molecular disponíveis para desnaturar proteínas enzimáticas. }\end{array}$ & $(95)$ \\
\hline $\begin{array}{l}\text { Presença de outras proteínas } \\
\text { enzimáticas }\end{array}$ & Desestabiliza & $\begin{array}{l}\text { Se acompanhadas de enzimas ou proteinases, podem degradar } \\
\text { a proteína enzimática adicionada. }\end{array}$ & $(96)$ \\
\hline Presença de Impurezas & Desestabiliza & $\begin{array}{l}\text { Danos químicos induzidos por radicais livres à enzima } \\
\text { (principalmente lipases), qualquer enzima por átomos de metais } \\
\text { pesados bloqueando o sitio ativo, metal que requerem enzimas } \\
\text { por agentes quelantes como o ácido cítrico ou polifosfatos. }\end{array}$ & $(97)$ \\
\hline
\end{tabular}


Quadro 3. Enzimas provenientes de plantas utilizadas na fabricação de alimentos.

\begin{tabular}{|c|c|c|c|c|}
\hline ENZIMAS & FONTE & AÇÃO ALIMENTOS & APLICAÇÃO & REFERENNCIAS \\
\hline Alfa-amilase & $\begin{array}{l}\text { Sementes de cereais } \\
\text { (milho) }\end{array}$ & $\begin{array}{l}\text { Hidrólise do amido em } \\
\text { polissacarídeos. }\end{array}$ & Malteação. & (99) \\
\hline Beta-amilase & Cevada & $\begin{array}{l}\text { Hidrólise do amido em maltose } \\
\text { pura. }\end{array}$ & $\begin{array}{l}\text { Produção de xaropes de alta } \\
\text { maltose. }\end{array}$ & $(100)$ \\
\hline Lipoxigenase & Trigo e Soja & $\begin{array}{l}\text { Oxidação de ácidos graxos } \\
\text { insaturados na farinha. }\end{array}$ & Melhora a massa do pão. & $(101)$ \\
\hline Bromelina & Suco de abacaxi e caule & $\begin{array}{l}\text { Hidrólise de proteínas musculares } \\
\text { e do tecido conjuntivo. }\end{array}$ & Tenderização de carne. & $(102)$ \\
\hline Papaína & $\begin{array}{l}\text { Látex dos frutos verdes } \\
\text { de papaia }\end{array}$ & $\begin{array}{l}\text { Hidrólise de proteínas em } \\
\text { alimentos e bebidas. }\end{array}$ & $\begin{array}{l}\text { Tenderização de carnes; } \\
\text { prevenção de névoa na cerveja. }\end{array}$ & (103) \\
\hline
\end{tabular}

Biossensores. Os biossensores representam uma alternativa promissora, devido à sua característica de facilidade de automação e construção de equipamentos simples e portáteis para um monitoramento rápido (104). De acordo com a União Internacional de Química Aplicada (IUPAC), os biossensores são caracterizados como dispositivos analíticos que incorporam um material biologicamente ativo a um transdutor que, por sua vez, converte a resposta da interação com o analito de interesse em um sinal elétrico passível de ser quantificado. Geralmente, a enzima interage de forma específica com um dado analito, fato este que permite o desenvolvimento de biossensores com elevada especificidade (105).

Biossensores são capazes de efetuar análises quantitativas ou semi-quantitativas específicas, integrando um elemento de reconhecimento biológico, no caso enzimas vegetais com um elemento apropriado de transdução de sinal. Os biossensores amperométricos destacam-se entre os demais biossensores, pela seletividade do agente de reconhecimento biológico (106).

Biossensores eletroquímicos contêm elementos de transdução de sinal em uma célula eletroquímica completa, sendo comumente aplicáveis a sistemas em fluxo
(38). Dividem-se em três categorias: amperométricos, potenciométricos e condutométricos. Sensores químicos são utilizados em diversas áreas: industriais (controle de processos, controle de qualidade dos produtos, controles ambientais), governamentais (monitoramento de emissões de automóveis, monitoramento de efluentes) e médicas (diagnósticos clínicos). Diante destas aplicações, sensores químicos tem resultado em benefícios econômicos e sociais $(107,108)$.

$\mathrm{O}$ uso de extrato bruto de vegetais como fonte enzimática para construção de biossensores tem se tornado frequente, devido à simplicidade e facilidade de obtenção da enzima, ao baixo custo do processo, à estabilidade e ao tempo de vida superior àqueles métodos que utilizam enzimas purificadas. Abacate, abobrinha, batata doce, banana, berinjela, jiló, pepino, vegetais disponíveis, podem ser matérias-primas para a construção de biossensores, podendo ser aplicados em análises de grande interesse nas áreas alimentícia, ambiental, biológica, farmacêutica e industrial, entre outras $(109,110,111)$. O Quadro 4 traz exemplos de biossensores enzimáticos desenvolvidos com extratos brutos vegetais.

Quadro 4. Biossensores baseados na extração de enzimas de vegetais.

\begin{tabular}{|c|c|c|c|}
\hline ENZIMA & FONTE VEGETAL & ANALITO/AMOSTRA & REFERÊNCIAS \\
\hline Polifenol oxidase & Solanum melongena (L.) Dunal & Determinação de paracetamol & $(27)$ \\
\hline Peroxidase & Phaseolus vulgaris (L.) Macfad & Determinação de agrotóxicos. & $(123)$ \\
\hline Urease & Canavalia ensiformis (L.) DC & $\begin{array}{l}\text { Determinação de ureia, ión amônio, gás amônia e } \\
\text { dióxido de carbono. }\end{array}$ & $(120)$ \\
\hline Peroxidase & Euterpe oleracea (L.) Mart. & Detecção de hexazinona. & $(124)$ \\
\hline Fenol oxidase & - & Detecção de pesticidas por métodos calorimétricos. & $(117)$ \\
\hline Polifenol oxidase & Musa acuminata (L.) Colla & Determinação de quinonas e compostos fenólicos. & $(125)$ \\
\hline Carboxilesterases & Arabidopsis thaliana (L.) Heynh & $\begin{array}{l}\text { Detecção e determinação de hidrolise de xenobióticos } \\
\text { e produtos naturais. }\end{array}$ & $(126)$ \\
\hline Peroxidase & Brassica rapa subsp. Rapa (L.) Metzg & Determinação de bioglicerideos em biodiesel. & $(111)$ \\
\hline
\end{tabular}


Tradicionalmente, as determinações são feitas com o emprego de enzimas já purificadas, com custos altos. Mas a utilização de tecidos ou extratos vegetais brutos, além de outras vantagens, faz com que os custos caiam a patamares mínimos, eliminando inclusive a necessidade de gastos com o processo de importação que, além de oneroso, é geralmente lento. Há diversas formas de se aplicar o tecido vegetal na confecção dos biossensores, sendo a utilização de extratos brutos enzimáticos imobilizados, a forma mais citada na literatura $(112,113$, 108, 111).

O principal problema durante o processo de imobilização de uma enzima pode ser a perda parcial ou total da atividade, que pode ser atribuída a diversos fatores, como propriedades da própria enzima, do suporte, dos reagentes utilizados e das condições experimentais. $\mathrm{O}$ desenvolvimento de técnicas de imobilização e purificação tem sido importante por proporcionar a reutilização das enzimas, aumentar a estabilidade, reduzir custos e aumentar, em alguns casos, a atividade enzimática. Esses fatores dependem principalmente da escolha apropriada do suporte e dos reagentes utilizados no processo de imobilização (109).

Biossensores utilizando extratos vegetais como fonte de peroxidase são muito comuns tendo inúmeras aplicações. Partindo do extrato bruto de jiló (Solanum gilo (L.) Rusby) foi imobilizada a enzima peroxidase com quitosana quimicamente interligada com picloridrina e glutaraldeído com a finalidade de determinar rutina em fórmulas farmacêuticas (114). E com extrato de nabo (Brassica napus (L.) Mill) foi possível analisar glicerídeos em amostras de biodiesel (111).

As polifenoloxidases têm sido utilizadas na preparação de biossensores e na identificação de compostos fenólicos e determinação de fenóis totais, em produtos e alimentos que têm este atributo como parâmetro representativo de sua capacidade antioxidante (115). Existem também vários outros usos como analisar quinonas, pesticidas e análise de águas residuais (116, 117, 118).

Com a enzima lacase é possível determinar compostos fenólicos em bebidas (sucos de frutas, vinho e cerveja) além de determinar a atividade antioxidante em vários outros produtos naturais $(119,105)$. A determinação de ureia, íon amônio, gás amônia e dióxido de carbono foi realizada com tecido vegetal imobilizado em rede de nylon por glutaraldeído. O biossensor teve vida útil de 70 dias, tendo resposta linear e concentração 1 a 20 ppm (120).
A enzima superóxido dismutase permite desenvolver um biossensor para determinação da atividade antioxidante de diversos produtos naturais (121). Ascorbato oxidase tem utilidade na identificação de ácido ascórbico, amplamente presente em diversas formulações terapêuticas devido ao seu alto potencial antioxidante $(63,104)$.

Alguns frutos do cerrado também já foram utilizados como base para extração de extratos vegetais para confecção de biossensores. Um exemplo é o trabalho de Lima e cols (2007), que imobilizaram polifenoloxidases de Pequi (Caryocar brasiliense Camb.) em quitosana reticulada em cloreto cianúrico para determinação de tiodicarbamato (122).

Biorremediação. A Biorremediação é uma tecnologia para tratar locais contaminados mediante o uso de agentes biológicos capazes de modificar ou decompor poluentes alvos. Consistindo no princípio da remoção de poluentes do ambiente natural e/ou a sua conversão em produtos menos prejudiciais, utilizando, para isso, comunidades de microrganismos endógenos do ambiente contaminados (127).

O objetivo da biorremediação no tratamento em áreas contaminadas é induzir ou acelerar os processos biológicos naturais de compostos de interesse, incluindo compostos orgânicos ou inorgânicos utilizando a capacidade intrínseca dos microorganismos de degradar matéria orgânica para degradar compostos orgânicos e inorgânicos tóxicos, tanto de origem natural como compostos sintéticos (128).

A biorremediação varia de acordo com o tipo de tratamento, as técnicas são denominadas in situ e ex situ, adotadas considerando não só os poluentes, mas o custo dos processos e, principalmente, a concentração final do contaminante, no término do tratamento, aceitável para o tipo de resíduo e para o uso futuro da área (129).

Este método de remover concentrações de poluentes tem sido recomendado pela comunidade científica, devido ao fato de não causar poluição secundária, ou causar menos. São métodos que podem ser implantados em águas superficiais e subterrâneas, solos e efluentes industriais (130).

Os fatores que podem influenciar a biodegradação, serão fatores físicos e químicos no qual vão depender da composição da matriz do ambiente (pH, salinidade, potencial oxirredução e outros), fatores extrínsecos (temperatura, umidade) e fatores relacionados ao poluente (estrutura química, presença de outros compostos, biodisponibilidade) (131) Cada processo de biorremediação é particular e quase sempre necessita de adequação e oti- 
mização específica para a aplicação em diferentes locais afetados, requerendo sempre uma análise integrada de parâmetros físicos, químicos e biológicos (132).

Para a implementação de um processo de biorremediação devemos levar em consideração primeiramente: a avaliação da natureza do composto, a caracterização da contaminação, o planejamento do tipo de biorremediação e a decisão por biorremediação in situ ou ex situ (127).

O ambiente é continuamente poluído por uma grande variedade de produtos nocivos, com diferentes estruturas e diferentes níveis de toxicidade que são liberados a partir de várias fontes antropogênicas e naturais. Três principais fontes antropogênicas de poluição podem ser identificadas: atividades industriais, lixo urbano, práticas agrícolas e transportes (133). O desenvolvimento acentuado da indústria química tem produzido uma grande variedade de substâncias que incluem pesticidas, combustíveis, solventes, alcanos, hidrocarbonetos aromáticos policíclicos (HAP), explosivos, corantes, outros. Embora estes compostos tenham contribuído para auxiliar o nosso estilo de vida, vários deles podem se acumular no solo, água e ar. Eles são altamente persistentes no meio ambiente e prejudica a saúde humana e ambiental, por causa de seus efeitos cancerígenos e mutagênicos (134).

Diversas estratégias foram concebidas para corrigir e restaurar ambientes poluídos: métodos físicos e químicos e abordagens biológicas, exigindo o envolvimento de agentes biológicos. O desenvolvimento das tecnologias limpas, ou seja, que reduzem o impacto ambiental de uma atividade industrial, também conta com a participação de enzimas. As enzimas são aplicadas ainda no tratamento de efluentes e resíduos industriais. As águas residuais das indústrias alimentícias, por exemplo, contêm gorduras sólidas ou líquidas (graxas e óleos), que causam sérios problemas de poluição, ao formar filmes na superfície dos corpos receptores (impedindo o fluxo do oxigênio necessário à vida aquática) e ao causar entupimentos $(128,130,133)$. A adição de lipases a esses efluentes gera substâncias mais simples, facilmente degradadas, evitando tais problemas.

A indústria têxtil é uma das maiores geradoras de efluentes líquidos, em geral tóxicos e contendo corantes (135). Tais resíduos são normalmente tratados por processos físico-químicos que precipitam e/ou coagulam parcialmente os resíduos, seguidos de tratamento biológico com lodos ativados, que contêm bactérias capazes de degradar as substâncias orgânicas ainda não removidas. Por isso, têm sido estudados vários microorganismos capazes de degradar poluentes têxteis com eficiência e baixo custo. Neste contexto as plantas também podem ser importantes na degradação desses contaminantes (134). Degradação de corantes têxteis mediadas por plantas com peroxidases, enzimas responsáveis pela catálise de reações de oxirredução, como é o exemplo da Ipomea palmata e da Saccharum spontaneum que podem ser usadas como alternativa para a descoloração de corantes têxteis, principalmente corantes azo, isso após o processamento de suas enzimas. Assim, tem sido empregada para diferentes fins como degradação de tinturas têxteis, como em muitas pesquisas também apontam como alternativa o uso de biossensores eletroquímos para a degradação de hormônio presentes na água potável (61) a utilização em eletrodos modificados para eletroanálise ambiental (136).

\section{CONCLUSÃO}

Considerando a grande complexidade e a importância da Enzimologia e suas aplicações na biotecnologia, o presente trabalho apresentou procedimentos analíticos empregados em tecidos e extratos brutos de vegetais. Em virtude da grande biodiversidade encontrada no Brasil, há certamente um número muito grande de procedimentos analíticos que poderão ser desenvolvidos utilizando enzimas vegetais com apelo sustentável. Características importantes como baixo custo e estabilidade fazem com que o emprego de tais materiais seja aplicado em diversas metodologias analíticas.

Por fim, esta revisão apresenta-se contextualizada frente aos processos de isolamento e purificação das enzimas vegetais de diversas fontes, bem como algumas de suas principais aplicações na biotecnologia do cenário atual.

\section{AGRADECIMENTOS}

Agradecimentos ao Conselho Nacional de Desenvolvimento Científico e Tecnológico - CNPq, pelo financiamento do projeto $456211 / 2014$ que possibilitou a realização deste trabalho. 


\section{REFERÊNCIAS}

1. Castro TC, Paula AMS, Gurgel CS, Albarello N. Micropropagação de plantas medicinais. Treinamento e capacitação de alunos de ciências biológicas na área de biotecnologia vegetal. Revista Aproximando. 2016; 2(3) 1-9.

2. Fonseca VB, Bobrowski VL. Biotecnologia na escola: a inserção do tema nos livros didáticos de Biologia. Acta Scientiae. 2015; 17(2) 496-509.

3. Conti R, Guimarães Do, Pupo MT. Aprendendo com as interações da natureza: microrganismos simbiontes como fontes de produtos naturais bioativos. Ciência e Cultura, São Paulo. 2012; 64(3): 43-47.

4. Albarello N, Simões-Gurgel C, Castro TC, Gayer CRM, Coelho MGP, Moura RS, Mansur E. Anti-inflammatory and antinociceptive activity of fieldgrowth plants and tissue culture of Cleome spinosa (Jacq.) in mice. Journal of Medicinal Plants Research. 2013; 7(16): 1043-1049.

5. Vieira IC, Lupetti KO, Fatibello-Filho O. Determinação de paracetamol em produtos farmacêuticos usando um biossensor de pasta de carbono modificado com extrato bruto de abobrinha (Cucurbita pepo). Quimica Nova. 2003; 26(1): 39-43. DOI: 10.1590/S010040422003000100009

6. Fermino-Junior PCP, Nagao EO, Scherwinski-Pereira JE. Estabelecimento, germinação e multiplicação in vitro de teca (Tectona grandis L.f.). Scientia Agricola. Piracicaba. 2009; 37(84): 427-435.

7. Talens-Perales D, Marín-Navarro J, Polaina J. Enzymes: Functions and Characteristics. Reference Module in Food Science. In: Encyclopedia of Food and Health. 2016; 1(1): 532-538. DOI: 10.1016/B978-0-12-3849472.00256-7

8. Polesel DN, Sinhorini ALC, Perone CAS. Caracterização cinética da enzima catecolase (Polifenol oxidase) em extratos brutos da polpa e da casca de berinjela (Solanum melongena L.). Jnl. Health Sci. Inst. 2010; 28(2) 175180.

9. Dittami SM, Edvardsen B. Culture conditions influence cellular RNA content in flagellates of the genus pseudochattonella (dictyochophyceae). Journal of Phycology, Oslo. 2012; 48(4): 1050-1055. DOI: 10.1111/j. 1529-8817.2012.01183.x

10. Merlin Christy P, Gopinath LR, Divya D. A review on anaerobic decomposition and enhancement of biogas production through enzymes and microorganisms. Renewable and Sustainable Energy Reviews. 2014; 34, p. 167-173.

11. Mahajan A, Kadavigere R, Sripathi S, Rodrigues GS, Rao VR, Koteshwar P. Utility of serum pancreatic enzyme levels in diagnosing blunt trauma to the pancreas: A prospective study with systematic review. Injury. 2014; 45(9): 1384-1393. DOI: 10.1016/j.injury.2014.02.014.

12. Yu Q, Yang H, Feng Y, Zhu Y, Yang X. Magnetic affinity enzyme-linked immunoassay based on recombinant
$26 \mathrm{kDa}$ glutathione-S-transferase for serological diagnosis of schistosomiasis japonica. Acta Tropica. 2012; 124(3): 199-202. DOI: 10.1016/j.actatropica.2012.08.006.

13. Carlos S. Biossensores Enzimáticos Baseados em Nanocompósitos Poliméricos. Rede de Nanotecnologia Aplicada ao Agronegócio Anais do V Workshop 2009. Anais do V Workshop. 2009.

14. Brandão MGL, Pignal M, Romaniuc S, Grael CFF, Fagg CW. Useful Brazilian plants listed in the field books of the French naturalist Auguste de Saint-Hilaire (17791853). Jnl. Ethnopharm. 2012; 143(2): 488-500.

15. George EF, Hall MA, De Clerk GJ. Plant propagation by tissue culture. The background. Springer, The Netherlands, 2008; 1(3). DOI: 10.1007/978-1-4020-5005-3.

16. Machado MS, Brancalion PHS, Potascheff CM, Santos AJB, Nave AG, Rodrigues RR, Gandolfi LS. Fenologia da frutificação de espécies vegetais nativas e a restauração florestal no arquipélago de Fernando de Noronha, PE, Brasil. Hoehnea. 2013; 40(3): 473-483.

17. Engelking LR. Chapter 5 - Properties of Enzymes. Textbook of Veterinary Physiological Chemistry. 2015; 1 : 26-31.

18. Bridel C, Courvoisier DS, Vuilleumier N, Lalive PH. Cerebrospinal fluid angiotensin-converting enzyme for diagnosis of neurosarcoidosis. Journal of Neuroimmunology. 2015; 285: 1-3. DOI: 10.1016/j.jneuroim.2015.05.020.

19. Duarte AR, Duarte DMR, Moreira KA, Cavalcanti MTH, Lima-Filho JL, Porto ALF. Jacaratia corumbensis O. Kuntze a new vegetable source for milk-clotting enzymes. Brazilian Archives of Biology and Technology. 2009; 52(1): 1-9. DOI: 10.1590/S1516-89132009000100001.

20. Cavell S, Scopes RK. Isolation and characterization of the 'photosynthetie' phosphoglycerate kinase from Beta vulgaris. European Journal of Biochemistry. 1976; 63: 483-490.

21. Sathyanarayana BN, Varghese DB. Plant Tissue Culture. Practices and new experimental. 2007; 316.

22. Jonsson I. Acid phosphatase from needles of Pinus slivestris L. Biochimica Biophysica Acta. 1981; 660: 204-213.

23. Hussain A, Qarshi IA, Nazir H, Ullah I. Plant Tissue Culture: Current Status and Opportunities. In: LEVA A, RINALDI LMR. Recent advances in plant in vitro culture. 1st edition. InTech, Croatia, 2012; 212. DOI: $10.5772 / 50568$.

24. Moss ML, et al. A colorimetric-based amplification system for proteinases including MMP2 and ADAM8. Analytical Biochemistry. 2015; 484: 75-81. DOI: 10.1016/j.ab.2015.05.011.

25. Thorpe TA. History of Plant Cell Culture. In: SMITH, R.H. Plant Tissue Culture. Techniques and Experiments. Academic Press, Third Edition. 2012; 188. DOI: 10.1016/B978-0-12-415920-4.00001-3. 
26. Neta LGS. Caracterização e avaliação do potencial de bioativos e atividade antioxidantes de Genipa americana desidratado. Salvador - Fundação de Amparo à Pesquisa do Estado da Bahia, 2014.

27. Garcia LF, Benjamin SR, Antunes RS, Lopes FM, Somerset VS, Gil ES. Solanum melongena polyphenol oxidase biosensor for the electrochemical analysis of paracetamol. Preparative Biochemistry and Biotechnology. 2016; 46(8): 850-855.DOI: 10.1080/10826068.2016.1155060.

28. Deutscher PM. Guide to protein purification. Imprenta. San Diego. Academic, 1990.

29. Guerra MP, Nodari RO. Apostila de Biotecnologia LFDGV/CCA/UFSC. Florianópolis: Edição da Steinmacher, 2006; 41.

30. Silva S, Neves RO, Ribeiro MS, Palhares MG, Maranhão MSA, Lobato RPF, Carlos F. Evaluation of Three Enzyme Immunoassays for Diagnosis of Clostridium difficile - Associated Diarrhea in Foals. Journal of Equine Veterinary Science.2014; 34(8): 1032-1035,

31. Yang S, Hai FI, Nghiem LD, Price WE, Roddick F, Moreira MT, Magram SF. Understanding the factors controlling the removal of trace organic contaminants by white-rot fungi and their lignin modifying enzymes: A critical review. Bioresource Technology. 2013; 141: 97108. DOI: 10.1016/j.biortech.2013.01.173.

32. Dixon WL, Webb EC. Cold-lability of phosphofructokinase from potato tubers. Phytochemistry. 1981; 20: 969972. DOI: 10.1016/0031-9422(81)83009-9.

33. Fagundes TS. Uso de Polímero Natural a Base de Amido como Auxiliar de floculação no pós-tratamento de efluentes UASB com Flotação por Ar Dissolvido, EESC/ USP, São Carlos - SP (monografia), 2010.

34. Rodrigues RT, Rubio J, Silva RDR.. Remoção da dureza da água por precipitação dos íons $\mathrm{Ca} 2+$ e $\mathrm{Mg} 2+$ e flotação por ar dissolvido - Processo PFAD. XVIII Congresso Brasileiro de Engenharia Química, Foz do Iguaçu-PR.2010; 2178-3659.

35. Leite JYP, Pinheiro VS. Qualidade da Água de Processo usada em Mineração - Estudo de caso da Mina Brejuí. IV Congresso de Pesquisa e Inovação da Rede Norte e Nordeste de Educação Tecnológica, Belém-PA. 2009.

36. Eiras DF, Craviotto MB, Baneth G, Moré G. First report of Rangelia vitalii infection (canine rangeliosis) in Argentina. Parasitol. Int. 2014; 63(5): 729-734. DOI: 10.1016/j.parint.2014.06.003.

37. Bhatia S, Othman Z, Ahmad AL. Pretreatment of palm oil mill effluent (POME) using Moringa oleifera seeds as natural coagulant. Journal of Hazardous Materials. 2007; 145: 120-126. DOI: 10.1016/j.jhazmat.2006.11.003.

38. Gallo M, Vinci G, Graziani C, Simone C, Ferranti P. The interaction of cocoa polyphenols with milk proteins studied by proteomic techniques. Food Res. Int. 2013; 54: 406-415. DOI: 10.1016/j.foodres.2013.07.011.

39. Loginov M, Boussetta N, Lebovka N, Vorobiev E. Separation of polyphenols and proteins from flaxseed hull extracts by coagulation and ultrafiltration. J. Membr. Sci. 2013; 442: 177-186. DOI: 10.1016/j.memsci.2013.04.036.

40. Lohaus G, Pennewiss K, Sattelmacher B, Hussmann $\mathrm{M}$, Muehling $\mathrm{KH}$. Is the infiltration centrifugation technique appropriate for the isolation of apoplastic fluid a critical evaluation with different plant species. Physiol. Plant. 2011; 111: 457-465. DOI: 10.1034/j. 1399-3054.2001.1110405.x.

41. Pegel A, Reiser S, Steurenthaler M, Klein S. Evaluating disposable depth filtration platforms for mab harvest clarification. Bio Process Int. 2011; 9(9): 52-55.

42. Ghorai S, Banik SP, Verma D, Chowdhury S, Mukherjee S, Khowala S. "Fungal biotechnology in food and feed processing”. Food Res. Int. 2009; 42(5): 577-587.

43. Han X, Chai X, Jia Y, Han C \& Tu P. "Structure elucidation and immunological activity of a novel polysaccharide from the fruit bodies of an edible mushroom, Sarcodon aspratus (Berk.) S. Ito". Int. J. Biol. Macromol. 2010; 47(3): 420-424. DOI: 10.1016/j.ijbiomac.2010.05.021.

44. Bitencourt EL. Prospecção química de carboidratos isolados dos basidiomas das linhagens branca e cinza do cogumelo medicinal grifola frondosa ("maitake"), Universidade Federal do Goiás. Catalão, 2015.

45. Koziorowski J. Simple method for the quality control of [18F] FDG, Appl. Radiat. Isot. 2010; 68(1): 1740-1742.

46. Farn S, Yeh Y, Lin W, Shen L. Development and validation of 2-deoxy-2-chloro-D-glucose impurity analysis in [18F] FDG by three potential-time waveforms of high-performance liquid chromatography/pulsed amperometric detection, Nucl. Med. Biol. 2009; 36(2): 225-231. DOI: 10.1016/j.nucmedbio.2008.11.008

47. Nakao R, Takehito Y, Masatoshi S, Kazutoshi I. Simultaneous analysis of FDG, ClDG and Kryptofix 2.2.2 in [18F] preparation by high-performance liquid chromatography with UV detection, Nucl. Med. Biol. 2008; 35(2): 239-244. DOI: 10.1016/j.nucmedbio.2007.11.003.

48. Paula AC, Melo KM, Silva AM, Ferreira DA, Monte FJQ, Santiago GMP, Lemos TLG, Braz-Filho R, Militão GEG, Silva PBN, Silva TG. Constituintes Químicos e Atividade Citotóxica de Cnidoscolus phyllacanthus. Revista Virtual Quimica. 2016; 8 (1), 231-241.

49. Newman D, Cragg GM. Natural Products as Sources of New Drugs over the 30 Years from 1981 to 2010. Journal of Natural Products. 2012; 75(3): 311-335.

50. Filietaz CFT, Lopes AR. Caracterização de Lipases em Arthropoda - Rev. Pesq. Inov. Farm.2010; 2(1): 23-36.

51. Fernandez MF, Sanroman MA, Moldes D. Recent developments and applications of immobilized lacase. Biotechnology Advances. 2013; 31(8): 1808-1825.

52. Gautam SS, Mishra SK, Dash V, Goyal AK, Rath G. Comparative study of extraction, purification and estimation of bromelain from stem and fruit of pineapple plant. Thai Journal Pharmaceutical Sciences. 2010; 34(2): 67-76. 
53. Peçanha BRB, Dias LRS, Spinelli E, Muri EMF. Polímeros de impressão molecular obtidos através de polimerização por precipitação e sua aplicação na técnica de extração em fase sólida. Polímeros. Ciência e Tecnologia. 2013; 23(4), 509-513.

54. Nelson DL, Cox MM. Princípios de bioquímica de Lehninger (5. ed.). Porto Alegre: Artmed. 2011.

55. Anastas P, Eghbali N. Green Chemistry: Principles and Practice. Chemical Society Reviews. 2010; v. 39(1): 301312. DOI: 10.1039/B918763B.

56. Borges ME, Bottoli BGC, Collins HC. Possibilidades e limitações no uso da temperatura em cromatografia líquida de fase reversa. Química Nova. 2010; 33(1): 945-953.

57. Clark HLM. Remoção de fenilalanina por adsorvente produzido a partir da torta prensada de grãos defeituosos de café (Dissertação de mestrado). Universidade Federal de Minas Gerais, Belo Horizonte. 2010.

58. Hazotte A, Libong D, Matoga M, Chaminade P. Comparison of universal detectors for high-temperature micro liquid chromatography. Journal of Chromatography A. 2007; 1170(1): 52-61. DOI: 10.1016/j.chroma.2007.09.008.

59. Lesellier, E.; West, C. The many faces of packed column supercritical fluid chromatography - A critical review. Journal of Chromatography A. 2015; 1382: 2-46. DOI: 10.1016/j.chroma.2014.12.083.

60. Maldaner L, Jardim ICSF. O estado da arte da cromatografia líquida de ultra eficiência. Química Nova. 2009; 32(1): 214-222.

61. Shaffiqu TS, Roy JJ, Nair RA, Abraham TE. Degradation of textile dyes mediated by plant peroxidases. Applied Biochemistry and Biotechnology. 2002; 102(1): 315326. DOI: 10.1385/ABAB:102-103:1-6:315.

62. Nadaroglu H, Celebi N, Demir N, Demir Y. Purification and characterisation of a plant peroxidase from rocket (Erucavesicariasb sp. Sativa) (Mill.) (syn. E. sativa) and effects of some chemicals on peroxidase activity in vitro. African Journal of Agricultural Research. 2013; 8(21): 2520-2528.

63. Dhar SC, Bose S. Purification and properties of ascorbic acid oxidase of avaram bark (Cassia auriculata) eather. Science Madras. 1966; 13(11): 317-324.

64. Luhova L, Sebela M, Frebort I, Zajoncova L, Faulhammer HG, PEC P. Screening of the occurrence of copper amine oxidases in Fabaceae plants. Biologia Plantarum. 1998; 41(2): 241-254.

65. Igamberdiev AU. Purification of plant enzymes by vesicle chromatography. Fiziologiya Rastenii, Moscow. 1993; 40(1): 146-149.

66. Meitinger N, Geiger D, Augusto TW, Maia De Padua $\mathrm{R}$, Kreis W. Purification of 5-3-ketosteroid isomerase from Digitalis lanata. Phytochemistry. Elsevier. 2015; 109(1): 6-13.
67. Ratnam S, Delcamp TJ, Hynes JB, Freisheim JH. Purification and characterization of dihydrofolate reductase from soybean seedlings. Archives of Biochemistry and Biophysics. 1987; 255(2): 279-89. DOI: 10.1016/00039861(87)90395-X.

68. Montalbini P, Redondo J, Caballero JL, Cardenas J, Pineda M. Uricase from leaves. Its purification and characterization from three different higher plants. Planta. 1997; 202(3): 277-283. DOI: 10.1007/s004250050129.

69. Mohamed SA, Almulaiky YQ, Ahmed YM, Al-Bar OAM, Ibrahim IH. Purification and characterization of $\alpha$-Amylase from Miswak Salvadora persica. BMC Complementary and Alternative Medicine. 2014; 14(1): 119. DOI: $10.1186 / 1472-6882-14-119$.

70. Chhetri DR, Yonzone S, Tamang S. Mukherjee AKL-myo-InositoL-1- phosphate synthase from bryophytes: purification and characterization of the enzyme from $\mathrm{Lu}$ nularia cruciata (L.) Dum. Brazilian Journal Plant Physiology. 2009; 21(3): 243-250.

71. Zerhouni S, Amrani A, Nijs M, Smolders N, Azarkan M, Vincentelli J, Looze Y. Purification and characterization of papaya glutamine cyclotransferase, a plant enzyme highly resistant to chemical, acid and thermal denaturation. Biochim Biophys Acta. 1998; 1387(1): 275-290. DOI: 10.1016/S0167-4838(98)00140-X.

72. Lubertozzi D, Keasling JD. Developing Aspergillus as a host for heterologous expression. Biotechnol Adv. 2009; 27(1) 53-75. DOI: 10.1016/j.biotechadv.2008.09.001.

73. Lemos JLS, Pereira-Junior N. Produção de xilanases por aspergillus awamori e a determinação do seu peso molecular por eletroforese em condições desnaturantes AS\&T. 2013; 1(1).

74. Ens S, Olson AB, Dudley C, Ross ND, Siddiqi AA, Umoh KM, Schneegut A. Inexpensive And Safe Dna Gel Electrophoresis Using Household Materials. Biochemistry Molecular Biology Education. 2012; 40(3): 198-203. DOI: $10.1002 / \mathrm{bmb} .20596$.

75. Ordonez EY, Rodil R, Quintana JB, Cela R. Determination of artificial sweeteners in beverages with green mobile phases and high temperature liquid chromatography - tandem mass spectrometry. Food Chemistry. 2015; 169: 162-168.

76. Filippoi PA, Santos GC, Graça FAZ, Nogueira AFS, Alves $\mathrm{AE}$, Santana AE. Proteinograma do líquido sinovial de equinos hígidos obtido por eletroforese em gel de poliacrilamida. Ciência Rural, Santa Maria. 2014; 44(7): 1268-1271.

77. Figueira PT. Caracterização eletroforética de proteínas musculares de aves de interesse comercial [dissertação]. Botucatu: Faculdade de Medicina Veterinária e Zootecnia, Universidade Estadual Paulista. 2011.

78. Moraes LB, Lubeck JCC, Ramos PRR, Roça RO, Figueira PT. Avaliação das perdas proteicas no post mortem de frangos de corte por método eletroforético. Vet. E Zootec. 2016; 23(1): 114-122. 
79. AOAC. Appendix F: Guidelines for standard method performance requirements. In: AOAC official methods of analysis, 2012.

80. Della Betta F, Vitali L, Fett R, Costa ACO. Development and validation of a sub-minute capillary zone electrophoresis method for determination of nitrate and nitrite in baby food.Talanta, Florianópolis. 2014; 122(1): 23-29. DOI: 10.1016/j.talanta.2014.01.006.

81. Coelho Mas, Salgado AM, Ribeiro BD. Tecnologia enzimática - Rio de Janeiro: FAPERJ; Petrópolis, RJ: EPUB. 2008: 264.

82. Camargo ER, Senseman SA, Mccauley GN, Bowe S, Harden J, Guice JB. Interaction between safl ufenacil and imazethapyr in red rice (Oryza ssp.) and hemp sesbania (Sesbania exaltata) as affected by light intensity. Pest Management Science, Hoboken. 2012; 68(7): 10101018.

83. SILVA FFM. Processos Biocatalíticos utilizando a casca da laranja da terra (Citrus Auramtium L.). Dissertação de Mestrado, Curso de Pós-Graduação em Química da Universidade Federal do Ceará. 2012.

84. Oliveira T M, Soares NFF, Paula CD, Viana GA. Uso da embalagem ativa na inibição do escurecimento enzimático de maçãs. Ciências Agrárias, Londrina. 2008; 29(1): 117-128,

85. Maeda RN, Barcelos CA, Santaanna LMM, Pereira JRN. Cellulase production by Penicillium funiculosum and its application in the hydrolysis of sugar cane bagasse for second generation ethanol production by fed batch operation. Biotechnology. 2013; 163: 38-44. DOI: 10.1016/j. jbiotec.2012.10.014.

86. Carvalho S. Pectinases produzidas pelo Agente "G088": Extração e purificação. Lavras Minas Gerais - Brasil, 2007.

87. Sharma DC, Satyanarayana TA. Marked enhancement in the production of a highly alkaline and thermostable pectinase by Bacillus pumilus dcsrl in submerged fermentation by using statistical methods. Bioresource Technology. 2006; 97(1): 727-733, DOI: 10.1016/j.biortech.2005.04.012.

88. Ahmed IAM, Morishima I, Babiker E E, Mori N. Characterisation of partially purified milk-clotting enzyme from Solanum dubium Fresen seeds. From Food Chemistry. 2009; 116(2): 395-400. DOI: $10.1016 /$ j.foodchem.2008.11.072.

89. Aplevicz, Krischina S. Fermentação natural em pães: ciência ou modismo. Aditivos \& Ingredientes. 2014; 105(1): 36-38.

90. Hawerroth MC, Barbieri RL, da Silva JAG, de Carvalho FIF, de Oliveira AC. Importância e dinâmica de caracteres na aveia produtora de grãos. Embrapa Clima Temperado. Documentos. 2014; 376.

91. ALIM MA, LEE JH, SHIN JA, LEE YJ, CHOI MS, AKOH CC, LEE KT. Lipase-catalyzed production of solid fat stock from fractionated rice bran oil, palm stea- rin, and conjugated linoleic acid by response surface methodology. Food Chem. 2008; 106(1): 712-719. DOI: 10.1016/j.foodchem.2007.06.035.

92. Knob A, Tombini J, Cunha MAA, Lima VA. Caracterização Bioquímica de Lipase Obtida por Fermentação do Farelo de Soja em Cultivo em Meio Sólido. V simpósio de bioquímica e biotecnologia, Londrina, PR, 2015.

93. Correia AC, Fonseca MMR, Ferreira-Dias S. Produção de Emulsionantes através da Glicerólise de Óleo de Bagaço de Azeitona Catalisada pela Lipase da Candida Rugosa Imobilizada em Espumas de Poliuretano. Millenium. 2011; 41(1): 7-15.

94. Campestrini, E. Farinha de carne e de ossos. Revista Eletrônica Nutritime. 2005; 2(4): 221-234.

95. Abdalla AL, Silva Filho JC, Godoi AR, Carmo CA, Eduardo JLP. Utilização de subprodutos da indústria de biodiesel na alimentação de ruminantes. Revista Brasileira de Zootecnia. 2008; 37(1): 260-258.

96. Carrazza LR, Silva ML, Ávila JCC. Manual Tecnológico de Aproveitamento Integral do Fruto do Babaçu. Brasília - DF. Instituto Sociedade, População e Natureza (ISPN). Brasil, 2012.

97. Stenzel M. Influência do tamanho das partículas na solubilização enzimática da proteína do farelo de soja proteína do farelo de soja. Acta Scientiarum. Maringá. 2009; 31(2): 195-200.

98. Sherzer ABI. Produção de Castanha do Brasil no território sul do Amapá: comparação entre o retorno econômico e o salário mínimo. Monografia (Especialização em Agronegócio). Universidade Federal do Paraná, PR. 2010.

99. Piovesan V. Milhos com diferentes texturas de endosperma e adição de alfa-amilase na dieta de leitões. Ciência Rural, Santa Maria 2011; 41(11).

100. Santos IJ. Expressão da alfa e beta amilase durante a germinação de cevada. Revista Brasileira de Produtos Agroindustriais, Campina Grande. 2010; 12(1): 67-73.

101. Dantas MIS. Farinhas mistas de trigo e de soja agregam valor nutricional e sensorial em pães. Rev. Inst. Adolfo Lutz. São Paulo. 2009; 68(2): 209-214.

102. Maciel AR. Amaciantes cárneos: tipos e aplicação em carne bovina. Revista Interdisciplinar da Universidade Federal do Tocantins. 2015; 2(1): 160-174.

103. Oliveira JD. Fatores determinantes da qualidade nutricional da carne bovina. Cadernos de Graduação - Ciências Biológicas e da Saúde. Aracaju; 2013; 1(16): 37-46.

104. Melo AF. Produção e aplicação de lípase no desenvolvimento de um biossensor potenciométrico. Tese de doutorado, Universidade Federal do Rio de Janeiro, 2012.

105. Mauricio EF, Silva LMC, Melo AF, Salgado AM, Pessoa FLP. Desenvolvimento de um Biossensor Enzimático para Degradação de Óleos Comestíveis. XXXV Jornada Giulio Massarani de Iniciação Científica, Artística e Cultural da UFRJ, Rio de Janeiro - RJ, 2013. 
106. SILVA LMC, SALGADO AM, COELHO MAZ. Development of an amperometric biosensor for phenol detection. Environm. Technology. 2011; 32(5): 493-497. DOI: $10.1080 / 09593330.2010 .504234$.

107. Alves CQ, Jorge MD, Juceni PD, Marcus VB, Rosane MA. Métodos para determinação de atividade antioxidante in vitro em substratos orgânicos. Quimica Nova. 2010; 33(10): 2202-2210.

108. Amare M, Admassie S. Polymer modified glassy carbon electrode for the electrochemical determination of caffeine in coffee. Talanta. 2012; 93(15), 122-128. DOI: 10.1016/j.talanta.2012.01.058.

109. Fatibello-Filho O, Vieira IC. Uso analítico de tecidos e de extratos brutos vegetais como fonte enzimática. Química Nova. 2002; 25(3): 455-464.

110. Arribas AS, Fernàndez $M$, Chicharro $M$. The role of electroanalytical techniques in analysis of polyphenols in wine. Trends in Analytical Chemistry. 2012; 34(1): 7896. DOI: 10.1016/j.trac.2011.10.015.

111. Mendes RK, Moino BP, Guilherme JPP, Nogueira AB. Desenvolvimento de um Biossensor Eletroquímico Obtido com Extrato Vegetal para a Determinação de Triglicerídeos em Biodiesel. Revista Virtual Química. 2014; 6(1): 1033-1046.

112. Matsumoto H, Nakazawa T, Ohta S, Terawaki Y. Chromosomal locations of catA, pobA, pcaA, dcu and Chu genes in Pseudomonas aeruginosa. Genetics Research. 1981; 38 (1): 251-266. DOI: 10.1017/S0016672300020590.

113. Moccelini SK, Spinelli A, Vieira IC. Biosensors based on bean sprout homogenate immobilized in chitosan microspheres and silica for determination of chlorogenic acid. Enzyme Microbiology Technology. 2008; 43(3): 81-387. DOI: 10.1016/j.enzmictec.2008.06.002.

114. Oliveira IRWZ, Vieira IC. Construção e aplicação de biosensores usando diferentes procedimentos de imobilização da peroxidase de vegetal em matriz de quitosana. Química Nova. 2006; 29(5): 932-939.

115. RODRÍGUEZ MC, RIVAS GA. Glassy carbon paste electrodes modified with polyphenol oxidase analytical applications. Analytica Chimica Acta. 2002; 459(1): 4351.

116. Signori CA, Fatibello-Filho O. Biossensor amperométrico para a determinação de fenóis usando um extrato bruto de inhame (Alocasia macrorhiza). Química Nova. 1994; 17(1).

117. Xu F, Jiang M, Xu Yi, Hua Z, Ma T. Calorimetric biosensor for rapidly detecting pesticides and preparation method there of. Faming Zhuanli Shenqing, CN 1987439 A 2007.

118. Carvalho IS, Silva R. In vitro Antioxidant Activity, Phenolic Compounds and Protective Effect against DNA Damage Provided by Leaves, Stems and Flowers of Portulaca oleracea (Purslane). Natural Product Communications. 2014; 9(1): 45-50.
119. Minussi RC, Pastore GM, Dura N. Potential applications of lacase in the food industry. Trends in Food Science \& Technology. 2002; 13(1): 205-216.

120. Flores RO, Silva LMC, Melo AF, Salgado AM. Analysis of Potential Applicability of the Potentiometric Urea Biosensor to Real Samples, 2013.

121. Campanella L, Bonanni A, Tomassetti M. Determination of the antioxidant capacity of samples of different types of tea, or of beverages based on tea or other herbal products, using a superoxide dismutase biosensor. Journal of Pharmaceutical and Biomedical Analysis. 2003; 32(1): 725-736. DOI: 10.1016/S0731-7085(03)00180-8.

122. Lima A, Silva AMO, Trindade RA, Torres RP, Mancini-Filho J. Composição química e compostos bioativos presentes na polpa e na amêndoa do pequi (Caryocar brasiliense, Camb.). Rev. Bras. Frutic. 2007; 29(3): 695698.

123. Mihos FC, Sá NC, Silva LMC, Salgado AM, Pereira PR. Purificação parcial da enzima peroxidase extraida do feijão (phaseolus vulgaris 1.) Visando aplicação em biossensor amperométrico para detecção de agrotóxicos. XX congresso brasileiro de engenharia química, 2014.

124. Toro MJU. Desenvolvimento de biossensores baseado em extrato de açaí e sensor biomimético para detecção de hexazinona. Tese apresentada ao Instituto de Química, Universidade Estadual Paulista, como parte dos requisitos parcial para obtenção do título Doutor em química. 2014.

125. Vasjari M, Parroj N. Phenolic biosensor based on carbon paste electrode modified with crude tissue. Department of Chemistry, Faculty of Natural Sciences, University of Tirana, Albania, 2012.

126. Cummins L, Landrum M, Steel PG, Edwards R. Structure activity studies with xenobiotic substrates using carboxylesterases isolated from Arabidopsis thaliana. Phytochemistry (Elsevier). 2007; 68(6): 811-818. DOI: 10.1016/j.phytochem.2006.12.014.

127. Barros CA. Um Estudo sobre Biorremediação: uma ciência levada à sala de aula. Monografia apresentada ao final do curso de Licenciatura em Química. Universidade Federal do Rio de Janeiro, 2007.

128. Adam G, Duncan H. Development of a sensitive and rapid method for the measurement of total microbial activity using fluorescein diacetate (FDA) in arange of soils. Soil Biol. Biochem. 2001; 33(7): 943-951.

129. Das N, Chandran P. Microbial Degradation of Petroleum Hydrocarbon Contaminants: An Overview. Biotechnology Research International. 2011. DOI: http://dx.doi. org/10.4061/2011/941810.

130. Fountoulakis MS, Terzakis S, Kalogerakis N, Manios T. Removal of poly-cyclic aromatic hydrocarbons and linear alkylbenzene sulfonates from domestic wastewater in pilot constructed wetlands and a gravel filter. Ecological Engineering, Holanda. 2009; 35(12): 1702-1709. 


\section{Initarma}

131. Megharaj M, Ramakrishnan B, Venkateswarlu K, Sethunathan N, Naidu R. Bioremediation approaches for organic pollutants: A critical perspective. Environment International. 2011; 37(8): 1362-1375. DOI: 10.1016/j. envint.2011.06.003.

132. Manfio GP. Aspectos biológicos e técnicas da biorremediação de xenobióticos. Biotecnologia, Ciência e Desenvolvimento. 2005; 8(34).

133. Sharma S. Bioremediation: features, strategies and applications.Asian. Journal of Pharmacy and Life Science. 2012; 2231: 4423.

134. Tyagi M, Fonseca MMR, Carvalho CCCR. Bioaugmentation and biostimulation strategies to improve the effectiveness of bioremediation processes. Biodegradation. 2011; 22(2): 231-241. DOI: 10.1007/s10532-010-9394-4.
135. Zhang Z, Gai L, Hou Z, Yang C, Ma C, Wang Z, Sun B, He X, Tang H, Xu P. Characterization and biotechnological potential of petroleum degrading bacteria isolated from oil-contaminated soils. Bioresource Technology. 2010; 101(1). DOI: 10.1016/j.biortech.2010.05.060.

136. Chrzanowski L, Lawniczak L, Czaczyk K. Why do microorganisms produce rhamnolipids. World Journal of Microbiology \& Biotechnology, Holanda. 2012; 28(2): 401-419. DOI: 10.1007/s11274-011-0854-8. 